$p=0.016)$ and weight $\left(R^{2}=15 \%, p<0.003\right)$ but not age $\left(R^{2}=4 \%\right.$, $\mathrm{p}>0.1$ ) or obesity (WC or BMI, both $\mathrm{p}>0.1$ ). On multivariate analysis GS T50 and GErate@T50 were negatively associated with male sex $\left(R^{2}=12 \%, p<0.005\right)$, height $\left(R^{2}=30 \%, p<0.001\right)$ and weight $\left(R^{2}=23 \%, p<0.001\right)$ but not age $\left(R^{2}=1 \%, p>0.1\right)$ or obesity (BMI or WC, both $\mathrm{p}>0.1$ ). Similar associations were not present with MRI indicating gastric content by GS and MRI do not provide the same information.

Conclusion HVs that are male, tall and heavy ingest more before MTV is reached; but no independent association with obesity was seen. These factors were associated with slower gastric emptying assessed by GS. A simple explanation is that large individuals have larger stomachs that can accommodate large volumes. $400 \mathrm{ml}$ achieves lower relative gastric filling in large than small stomachs and does account also for slower GE.

Competing interests None declared.

\section{PWE-050 DOES SMALL INTESTINE BACTERIAL OVERGROWTH CAUSE NEURODYSMOTILITY IN IBS AND COELIAC DISEASE?}

doi:10.1136/gutjnl-2012-302514d.50

K Evans, ${ }^{*}$ E Lunn, S Raza, D S Sanders, S Higham. Sheffield teaching hospitals NHS Trust, Sheffield, UK

Introduction Small intestine bacterial overgrowth (SIBO) has been proposed as a cause of altered small bowel motility both in irritable bowel syndrome (IBS) and coeliac disease. The glucose hydrogen breath test (GHBT) is most commonly used in practice to diagnose SIBO. The aim of this study was to assess the prevalence of SIBO using GHBT in coeliac disease and IBS.

Methods Group A comprised patients with biopsy-proven, untreated coeliac disease $(n=44,14$ male, median age $47 y$, range 18-75). Group B comprised patients with IBS ( $\mathrm{n}=207,55$ male, median age 53 y, range $17-90)$. Group C comprised controls $(n=47$, 9 male, median age 58 years, range 20-74). All had GHBT performed on a normal, gluten containing diet. In the coeliac group this was repeated after a median of 180 days on a gluten-free diet (GFD). None had antibiotics in the 4 weeks prior to testing. A positive result was a rise in hydrogen of at least $20 \mathrm{ppm}$, or methane of $12 \mathrm{ppm}$, over the baseline for each gas.

Results 6/44 (13.6\%) with coeliac disease had a positive result. 30/ 207 (14.5\%) patients with IBS had a positive breath test. 1/47 (2.1\%) controls tested positive. Patients with coeliac disease $(p=0.05)$ and IBS $(p=0.02)$ were significantly more likely than controls to have a positive GHBT. In the coeliac group positive GHBT was associated with male sex but no other features. There were no associated features in groups B and C. Patients with coeliac disease had lower baseline hydrogen levels $(9.4 \mathrm{ppm} \pm 8)$ compared with IBS patients (13.4 ppm \pm 13.7$)(\mathrm{p}=0.07)$ and controls (16.6 ppm \pm 18.0$)$ $(p=0.025)$. In the coeliac group $4 / 6$ with a positive result had a significant rise in methane but not hydrogen. At repeat testing all four were persistently methane positive but the absolute peak methane levels had fallen from a mean of $64 \mathrm{ppm}$ to a mean of $49 \mathrm{ppm}$. Only one coeliac subject had a positive GHBT that normalised on GFD.

Conclusion The prevalence of SIBO diagnosed by GHBT is similar in IBS and coeliac disease. SIBO is significantly more common in IBS and coeliac disease than in controls. The prevalence of SIBO in coeliac disease may not vary between treated and untreated disease. Despite this increased prevalence of SIBO in coeliac disease and IBS, the failure of prevalence to fall following GFD may suggest that neurodysmotility is not the method for symptoms in these patients.

Competing interests None declared.

\section{PWE-051 STUDIES OF THE PSYCHOPHYSIOLOGICAL MARKERS AND THE BRAIN PROCESSING OF NAUSEA IN HEALTHY HUMANS USING A NOVEL VIRTUAL REALITY VIDEO}

doi:10.1136/gutjnl-2012-302514d.51

${ }^{1} \mathrm{~K}$ S Ng, ${ }^{*} \mathrm{~S} J$ Coen, ${ }^{1} \mathrm{Y}$ C Chua, ${ }^{1} \mathrm{~V}$ F Ban, ${ }^{2} \mathrm{M}$ A Gresty, ${ }^{1} \mathrm{G} J$ Sanger, ${ }^{3} \mathrm{~S} C$ Williams, ${ }^{3} \mathrm{G} \mathrm{J}$ Barker, ${ }^{4} \mathrm{P} \mathrm{L}$ Andrews, ${ }^{1} \mathrm{M}$ Imran, ${ }^{1} \mathrm{O}$ Aziz. ${ }^{1}$ Wingate Institute of Neurogastroenterology, QMUL, London, UK; ${ }^{2}$ Division of Neurosciences and Mental Health, Imperial College, London, UK; ${ }^{3}$ Institute of Psychiatry, King's College, London, UK; ${ }^{4}$ Division Of Biomedical sciences, St George's University, London, UK

Introduction Nausea is a common and complex multi-system sensation. Objective psychophysiological markers of nausea that also predict nausea susceptibility in humans are lacking. The regions of the brain that process the sensation of nausea are also unknown. Using a novel model of motion sickness induced nausea, we aimed to study psychophysiological and brain responses during nausea in healthy human volunteers.

Methods A 10-min video of motion and a control video of a still image were presented to 98 healthy volunteers (age $26 \pm 8$ years, 53 male). Validated questionnaires were used for anxiety and nausea assessment. We monitored sympathetic activity [heart rate (HR) and mean, systolic and diastolic blood pressure (MBP, SBP and $\mathrm{DBP})$ ]; parasympathetic activity [cardiac vagal tone (CVT), cardiac sensitivity to baroreceptor reflex (CSB)], electrogastrogram (EGG) and blood cortisol. Comparisons of these parameters were made in the 25 most susceptible and the 25 most resistant subjects (nausea VAS). 28 subjects of the 50 (aged $25 \pm 5$ years, 16 males, 11 nausea resistant) repeated the experiments with Functional MRI to assess brain activity during nausea.

Results All subjects completed the studies without vomiting. Comparison of motion video (MV) to control: MV raised nausea scores (nausea VAS, $+57 \% \pm 11$, pComparison of nausea susceptible (NS) with resistant subjects (NR): the NS subjects showed more parasympathetic withdrawal; larger sympathetic activation and higher cortisol release and trend for higher EGG activity in comparison to NR subjects (Abstract PWE-051 table 1). Brain imaging data (all results had corrected $\mathrm{p}$ : There was a positive correlation between brain activity and nausea level in the inferior frontal gyrus; and a negative correlation in declive, culmen, cuneus, and parahippocampal gyrus in NS subjects. Compared to NR subjects, NS volunteers showed increased activity in the substantia nigra; and decreased activity in declive and parahippocampal gyrus during nausea induction.

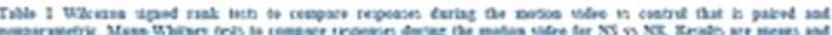
maturs eree ef mens.

\begin{tabular}{|c|c|c|c|c|c|c|c|c|}
\hline & $\begin{array}{c}\text { CVT X } \\
\text { charge }\end{array}$ & $\begin{array}{c}\operatorname{css} x \\
\text { change }\end{array}$ & $\begin{array}{c}\text { MR S } \\
\text { Change }\end{array}$ & $\begin{array}{c}\text { MLOX } \\
\text { change }\end{array}$ & $\begin{array}{c}\text { Sap X } \\
\text { change }\end{array}$ & $\begin{array}{l}\text { Dows } \\
\text { Change }\end{array}$ & $\begin{array}{c}\text { Cortisol } \\
\text { change } \\
\text { chang }\end{array}$ & $\begin{array}{c}\text { ECC } \\
\text { (sweles } \\
\text { per } \\
\text { minute) }\end{array}$ \\
\hline $\begin{array}{l}\text { Mobon } \\
\text { video }\end{array}$ & $\begin{array}{c}-957 \pm \\
274\end{array}$ & $\begin{array}{r}-15.14 \\
+\quad 311 \\
\end{array}$ & $\begin{array}{c}6.16 \pm \\
0.92\end{array}$ & $\begin{array}{c}5.45 \pm \\
0.89\end{array}$ & $\begin{array}{c}4.13 t \\
0.91\end{array}$ & $\begin{array}{c}6.82 \pm \\
104 \\
\end{array}$ & $\begin{array}{l}764 \pm \\
1762\end{array}$ & $3.0 \pm 0.04$ \\
\hline $\begin{array}{c}\text { Neured } \\
\text { video }\end{array}$ & $\begin{array}{c}0.392 \\
2.33\end{array}$ & $\begin{array}{c}0.35 \mathrm{z} \\
3.28\end{array}$ & $\begin{array}{l}1.361 \\
0.55\end{array}$ & $\begin{array}{l}0.512 \\
0.66\end{array}$ & $\begin{array}{l}0.76: \\
0.72\end{array}$ & $\begin{array}{c}0.301 \\
0.68\end{array}$ & $\begin{array}{c}-28.55 \\
5.12\end{array}$ & $2.8 \pm 0.05$ \\
\hline $\begin{array}{l}\text { Mobon vs } \\
\text { Neutal }\end{array}$ & .996 & .14 .79 & 5.40 & 4.94 & 3.37 & 660 & 35.19 & 0.2 \\
\hline $\begin{array}{c}\text { Wiscoxon } \\
\text { Signed } \\
\text { Rank }\end{array}$ & $p<0.01$ & $p<0.01$ & peo.01 & $p<0.01$ & $p=0.00$ & pe001 & $p=0.09$ & $p<0.02$ \\
\hline $\begin{array}{c}\text { Nausea } \\
\text { surceptbin }\end{array}$ & $\begin{array}{r}-20.63 \\
\pm 4.12\end{array}$ & $\begin{array}{l}-27.64 \\
+5.14\end{array}$ & $\begin{array}{r}11.05 \\
+236\end{array}$ & $\begin{array}{c}7731 \\
221\end{array}$ & $\begin{array}{c}5.67 \% \\
2.10\end{array}$ & $\begin{array}{c}9941 \\
261\end{array}$ & $\begin{array}{c}1794 x \\
2261\end{array}$ & $3.1 \pm 0.05$ \\
\hline $\begin{array}{l}\text { Nausea } \\
\text { Resotare }\end{array}$ & $\begin{array}{c}-503 \mathrm{x} \\
335 \\
\end{array}$ & $\begin{array}{c}-7.08 \mathrm{t} \\
4.06 \\
\end{array}$ & $\begin{array}{c}4521 \\
130\end{array}$ & $\begin{array}{c}269 x \\
158\end{array}$ & $\begin{array}{c}1.47 \mathrm{t} \\
1.70\end{array}$ & $\begin{array}{c}4.121 \\
172\end{array}$ & $\begin{array}{c}-21931 \\
587\end{array}$ & $2.8 \pm 0.07$ \\
\hline $\begin{array}{c}\text { Suscepobic } \\
v 5 \\
\text { Resistare }\end{array}$ & .15 .60 & -20.56 & 6.64 & 6.04 & 4.20 & 5.82 & 39.87 & 0.3 \\
\hline $\begin{array}{l}\text { Mann- } \\
\text { Whibrey }\end{array}$ & $p 00.01$ & $p<0.01$ & $p \infty 03$ & $p=0.10$ & $p=0.17$ & $p=0.09$ & $p 0005$ & $p=0.06$ \\
\hline
\end{tabular}

Conclusion NS subjects decreased PNS tone and increased SNS tone, anxiety and cortisol suggesting these parameters could be markers of nausea susceptibility. The NS subjects also showed different brain processing patterns compared to NR subjects. Thus, this safe and 
effective model for inducing nausea without vomiting can be used to study effects of nausea on GI function together with correlations with objective physiological and brain activity markers. The markers identified may help to reduce and refine animal experiments.

Competing interests None declared.

\section{PWE-052 PHENOTYPING THE EARLY MORNING RUSH (EMR) IN PATIENTS WITH DIARRHOEA PREDOMINANT IRRITABLE BOWEL SYNDROME (IBS-D)}

doi:10.1136/gutjnl-2012-302514d.52

${ }^{1} \mathrm{~K}$ Garsed, ${ }^{*}{ }^{2} \mathrm{M}$ Hastings, ${ }^{1} \mathrm{C}$ Lam, ${ }^{2} \mathrm{P}$ Whorwell, ${ }^{1} \mathrm{R}$ Spiller. ${ }^{1}$ Nottingham Digestive Diseases Centre NHIR BRU, University of Nottingham, Nottingham, UK; ${ }^{2}$ Neurogastroenterology and Motility, Wythenshawe Hospital, Manchester, UK

Introduction A proportion of patients with IBS-D describe frequent bowel movements first thing in the morning. While most clinicians recognise the phenomenon there is currently no definition of this "early morning rush" and no data describing the subgroup of patients who experience this disabling symptom which frequently impacts on their quality of life and ability to work

Methods 119 patients meeting the Rome 3 criteria for IBS-D and 20 age and sex matched healthy volunteers (HV) completed a 1-week stool diary, hospital anxiety and depression score (HADS), and personal health questionnaire (PHQ-12). They also completed an IBS severity score (IBSSS) and IBS quality of life score (IBSOOL) as part of entry into a clinical trial. Whole gut transit (WGT) was measured during the placebo arm using the radio-opaque marker method. EMR was defined as $\geq 2$ bowel movements within $1 \mathrm{~h}$, between midnight and midday. Patients and HV were divided into 3 subgroups, those with $\leq 2$ days/week $E M R=$ normal morning rush (NMR), those with 3-4 days/week EMR = moderate morning rush (MMR), and those with 5-7 days/week with EMR = severe morning rush (SMR). Results $16 \%$ of patients had MMR and $15 \%$ of patients had SMR, all HV had NMR. Those with SMR had greater psychological distress (sum of the HADS score) than those with NMR, 19.11 $( \pm 1.8)$ vs $13.48( \pm 0.8) \mathrm{p}=0.021$, and more somatic symptoms (PHO-12), $9.2( \pm 0.9)$ vs $6.5( \pm 0.4) \mathrm{p}=0.02$. The SMR group had greater mean daily stool frequency than those with NMR and MMR $5.6(3.5-8.2)$ vs $2.14(1.7-3.0)$ and $3.7(2.7-4.4) \mathrm{p}<0.0001$ with a higher IBSSS $366( \pm 18.4)$ vs $296.6( \pm 9.4)$ and 295.9 ( \pm 17.2$)$ $\mathrm{p}=0.005$, this was accompanied by a lower IBSQOL $334.3( \pm 21.1)$ vs 467.3 ( \pm 17.9$)$ and $467.3( \pm 33.4) \mathrm{p}=0.004$. WGT (in hours) was significantly faster in the SMR group $7(5.5-15)$ vs $19(10-39)$ in the NMR and $16(8.5-24.5)$ in the MMR groups $p=0.03$.

Conclusion Around $1 / 3$ of IBS patients suffer from early morning rush. Those severely affected represent a group with a worse quality of life, greater psychological distress and more somatic symptoms. This is associated with faster whole gut transit and increased stool frequency. A third of the patients with SMR dropped out of the trial compared to $<10 \%$ in the other groups making this a challenging subgroup to study.

Competing interests None declared.

\section{PWE-053 CYCLIC VOMITING SYNDROME IN 28 PATIENTS: DEMOGRAPHICS, FEATURES AND OUTCOMES}

\section{doi:10.1136/gutjn-2012-302514d.53}

${ }^{1} \mathrm{~L}$ Lee, * ${ }^{1} \mathrm{~L}$ Abbott, ${ }^{2} \mathrm{~J}$ Burnett, ${ }^{3} \mathrm{~S}$ Anderson, ${ }^{1} \mathrm{~S}$ Moodie. ${ }^{1}$ Department of Gastroenterology, Epsom and St Helier University Hospitals NHS Trust, London, UK; ${ }^{2}$ Guy's and St Thomas' NHS Foundation Trust, London, UK; ${ }^{3}$ Department of Gastroenterology, Guy's and St Thomas' NHS Foundation Trust, London, UK

Introduction Cyclic Vomiting syndrome (CVS) is a condition characterised by recurrent, stereotyped attacks of intense nausea and intractable vomiting with no identifiable organic cause. The diagnosis of CVS has been helped by the Rome III diagnostic criteria, however, the condition is still a very heterogeneous group of symptoms and there have been very little studies analysing in detail patient-reported features. There is now some evidence for the role of tricyclic antidepressants in managing these patients, but as yet, there is no evidence on the long-term outcomes of patients treated conservatively.

Methods This was a retrospective cohort study of all patients treated at two London teaching hospitals. Information was gathered by means of inpatient case notes, clinic letters and telephone interviews with standardised questions.

Results 28 patients were identified, 17 with adult onset-CVS and 11 with childhood-onset CVS. Overall, $54.5 \%$ of patients noted that each attack occurred at the same time of day, usually between 4:00-6:00. In the adult-onset CVS cohort, the average age of onset was 30.9 years; the prevalence of headache was $57.1 \%$. Vomiting attacks occurred on average 10 times a year with a mean duration of $55.3 \mathrm{~h}$. In the childhood-onset CVS cohort, the average age of onset was 5.7 years and the prevalence of headaches was $44.4 \%$. Vomiting attacks occurred on average 25.5 times a year with a mean duration of $54.5 \mathrm{~h}$. During acute admissions patients rated morphine-based medications and ondansetron as most effective. Long-term, $65.4 \%$ of our patients were treated conservatively and of these $42.1 \%$ felt their symptoms had improved and a further $23.8 \%$ noted that their symptoms had resolved completely.

Conclusion Cyclic Vomiting Syndrome is a debilitating illness with a high impact on patient's quality of life. There is a high association with anxiety/depression as well as headaches. Morphine based medications are the most efficacious symptomatic acute treatment. Conservative management has a role to play in the long-term treatment of these patients. The prognosis of these patients is good with nearly $70 \%$ of patients having an improvement in their symptoms and nearly a quarter having resolution of the condition after 7 years.

\section{Abstract PWE-053 Table 1}

\begin{tabular}{lccc}
\hline & Overall & Adults & Children \\
\hline No/year, mean (SD) & $16.3(22.9)$ & $10.0(12.1)$ & $25.5(31.4)$ \\
Duration, mean hours (SD) & $55(43.8)$ & $55.3(39.9)$ & $54.5(50.7)$ \\
Vomiting freq, mean (SD) & $4.1(2.6)$ & $3.5(1.7)$ & $4.6(3.3)$ \\
Duration of recovery phase, mean hours (SD) & $53.2(47)$ & $59.1(43.6)$ & $45(53.2)$ \\
\hline
\end{tabular}

Competing interests None declared.

\section{PWE-054 THE MANAGEMENT OF CYCLIC VOMITING SYNDROME: A SYSTEMATIC REVIEW OF 1141 CASES}

doi:10.1136/gutjnl-2012-302514d.54

L Lee, ${ }^{*}$ L Abbott, B Mahlangu, S Moodie. Epsom and St Helier University Hospitals NHS Trust, London, UK

Introduction Cyclic Vomiting syndrome (CVS) is characterised by recurrent attacks of intractable vomiting with no identifiable organic cause. It can take years before CVS is diagnosed, furthermore there have only been a handful of case studies looking at management strategies to reduce the duration/frequency or intensity of cyclic vomiting attacks. The objectives of this review were to identify associated clinical features that would help suggest a diagnosis of CVS and to review the literature to identify management strategies with the highest efficacy.

Methods A literature search was performed using the databases MEDLINE via Ovid (1948 to October 2011) and EMBASE (1980 to October 2011). The search terms included "Cyclic" and "Vomiting". 